\title{
Beauty and Happiness: The Payoff of Good-Looking
}

\author{
Wei-Lun Chang \\ Tamkang University, Taiwan, Providence of China
}

Doi:10.5296/ijhrs.v3i4.4551

URL: http://dx.doi.org/10.5296/ijhrs.v3i4.4551

\begin{abstract}
The economics of beauty has been an emerging issue recently. Report revealed handsome and beautiful people earn more than ordinary. This research investigated the correlation between personal traits and beauty as well as happiness. We aim to discover (1) what are the personal traits and the degree of beauty that influence happiness and (2) what are the personal traits and degree of happiness that influence beauty. We used synthesized data mining techniques (clustering and classification) to discover the significant traits that are associated with beauty and happiness. The results reveal that females are happier than males in Taiwan. People who work in service industry are more beautiful than other industries. Senior managers are happier than rookie employees. We infer that good-looking results in high self-confidence and can earn more opportunities for job, income, or spouse. Our result also complies with the outcomes of existing researches. Hence, this research provides a roadmap to analyze the influence of beauty and happiness in workplace for future researches.
\end{abstract}

Keyword: Beauty, Happiness, Self-Organization Maps, Decision Tree Classification

\section{BACKGROUND}

The economics of beauty has been an emerging research issue recently. Certain researches revealed the look of human being indeed affects economic behavior. For example, Hamermesh (2011) indicated the income of handsome and beautiful people is higher than homely people; in particular, $17 \%$ (men) and 12\% (women) respectively. Rhode (2011) also specified females rather be hit by a truck than be fat and $90 \%$ of females were willing to have surgery for beauty. Hence, good-looking people have better lucks and higher income. According to the report from NY Times (2011), women pay averagely 449,127 USD to maintain beauty in the entire life. Women's looks have bigger impacts for mates and men's looks have bigger impacts on the job. Varian (2006) also indicated good-looking is strongly associated with self-confidence, which is apparently attractive to employers. Particularly, the scale of plastic surgery in United States is 10.1 billion USD annually and 91\% of customers are women.

Hamermesh (1994) firstly investigated the look in labor market. The results revealed handsome and beautiful people earned more money and found better spouses, which may cause happiness. Biddle and Hamermesh (1998) also indicated the causal relationship indeed existed between beauty and salary. The result clearly revealed the discrimination of look is serious in labor market. In addition, Pfann, Biddle, and Hamermesh (2000) investigated 
CEOs and managers and the outcome showed the look of managers also influenced the revenue of companies. That is, more handsome and beautiful CEOs can help companies generate more profit. The research of Croucher (2009) showed $80 \%$ of good-looking people have better job interview opportunities, $10 \%$ of people were willing to do plastic surgery to increase job opportunities, and $75 \%$ of people believed good-looking may have better chances of life. Andreoni and Petrie (2008) proved appealing and good-looking people can earn more $12 \%$ of salary. In practice, Abercrombie \& Fitch and Victoria Secret both hire appealing and good-looking models. Hammermesh and Abrevay (2011) examined the connection between look and happiness by regression. The results reveal beauty affected happiness because good-looking people have higher chances to achieve the goals and finding better spouses.

Certain literature proved look may influence job opportunities and salary in the labor market. Many doctors are also willing to change their career to cosmetic surgery or plastic surgery recently because beauty may be the path to happiness. However, the relationship between beauty and happiness still needs more investigation. In this research, we aim to discover (1) what are the personal traits and the degree of beauty that influence happiness and (2) what are the personal traits and degree of happiness that influence beauty. Different from researches using statistics, the present research uses a synthesized approach from data mining: unsupervised clustering and supervised classification. The goals are to separate participants into groups and discover the strong personal traits that affect beauty and happiness. The comparison of different groups with different personal traits to affect beauty and happiness will also be provided to researchers and practitioners.

The remaining of this paper is organized as follows. Section 2 discusses the research framework and proposed methods. Section 3 furnishes data analysis in terms of data collection, demographics and outcomes of analysis. Section 4 provides a brief discussion of cross analysis. Finally, section 5 concludes with a summary and limitations.

\section{METHODOLOGY}

\section{Research Framework}

Figure 1 illustrates the proposed research framework. The synthesized approach includes two steps: clustering and classification. The first step is clustering method by using self-organization maps. The goal is to analyze personal traits, degree of beauty, and degree of happiness and form groups (clusters) automatically. The second step is classification by using decision tree. The goal is to construct trees with rules of each group. Moreover, the identified traits that are associated with beauty or happiness are revealed in the classification rules. Hence, the synthesized approach can automatically separate data into groups and identify the traits that are significant to influence beauty or happiness respectively. The idea of synthesized approach with two data mining concepts is widely used in existing researches. Moreno, Marco, and Olmeda et al. (2005) used self-organization maps to evaluate the official Spanish mutual funds classification. Nohuddin, Coenen, Christley, Setzkorn, Patel, and Williams (2012) combined association rule and self-organization maps to tightly group the identified rules for social networks. Kumar and Ravi (2007) used statistical and intelligent techniques (e.g., neural networks and decision trees) for bankruptcy prediction in banks and 
firms. Isa, Kallimani, and Lee (2009) combined self-organization maps and Bayes formula to cluster text documents. Astudillo and Oommen (2011) proposed a tree-based topology-oriented self-organization maps to improve the efficiency of current algorithms. Liu (2009) used self-organization maps and data mining models to support for liability authentications of traffic crashes. That is, existing researches showed the feasibility for combining two data mining techniques and the effectiveness of the combined approach.

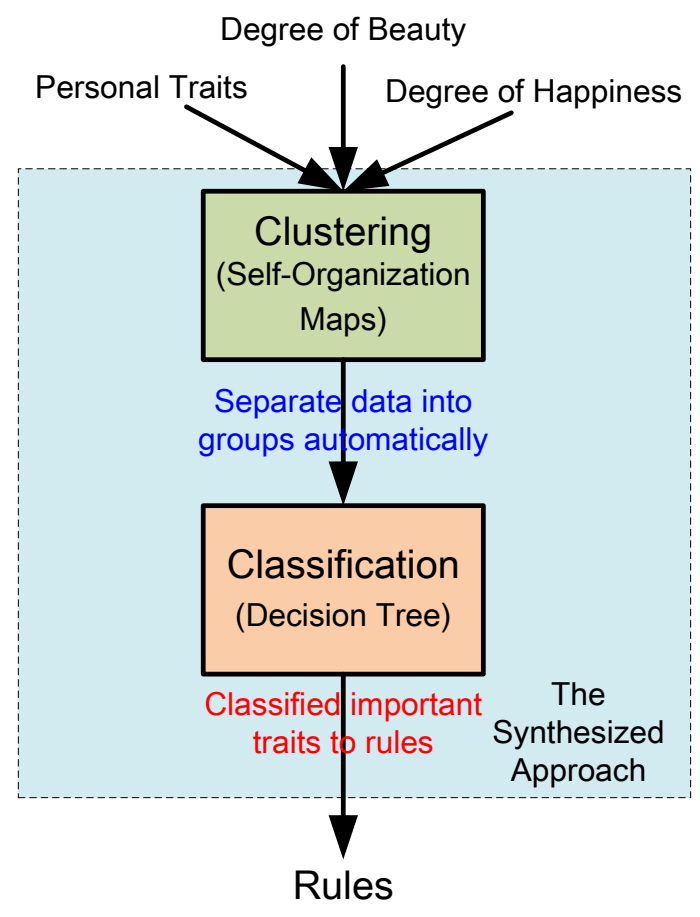

Figure 1 Research Framework

\section{Research Methods \\ Self-Organization Maps}

Self-Organization Maps (SOM) is a principle that was introduced in early 1981 by Kohonen (1990), and is a mechanism that organizes automatically high-dimensional statistical data. The concept is that inputs of data will be represented on a tridimensional map and outputs would later be represented on a grid-like map characteristic. Self-organization maps is a type of competitive learning. Competitive learning is a scheme of unsupervised learning in artificial neural networks and works by increasing the tuning of each node in the network, through the training process it will get better tuned to perform its tasks. The process of competitive learning is well suited to finding clusters within data (Rumelhart \& McClelland, 1986). The main task of the SOM is to represent the input in terms of a similar map based on an unsupervised learning process. Similar inputs are concentrated together in what is called neighborhoods. The ability to locate these clusters or neighborhoods of input cells is one of the main properties of SOM (Lagus et al., 1996). Kohonen (1990) stated that the two main effects generated by SOM are (1) spatial concentration of the network activity on the cells or their neighborhoods that are best tuned to the present input data, and (2) further tuning of the best-matching cells and their topological neighbors to the present input data. 
In SOM, we assume that each unit contains an input vector and a weight vector. These vectors will represent the data and will change gradually until they form an organized non-linear representation of the input data (Lagus et al. 1996). Through SOM, it is also possible to calculate a general distance measure between cells in the network. SOM utilizes the Euclidean distance concept to calculate the distance between input cells in the network. The training phase of the SOM compares the input vectors with the weight vectors of each data unit as they approach the competitive phase. The goal is to discover the ultimate winner among neurons abiding by the competitive learning approach. The unit, or neuron, with the weight vector most close to its input vector is considered the winning unit. That is, the smallest difference between the input vector and the weight vector. In SOM, the winner is also called the best-matching unit (BMU) (Zhao et al., 2011). Figure 2 illustrates the difference between the BMU and the losing units in that map. BMU is the one with the shortest distance among vectors.

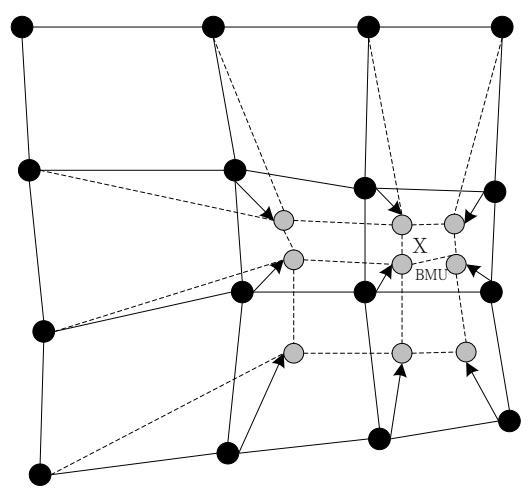

Figure 2 Concept of Best-Matching Unit in Learning Process

The next step in SOM process is to adjust the distance between the BMU and its neighboring neurons. The neighborhood function is used, which is also a decreasing function, representing to what level the unit is updated when the BMU unit is found to be the winner. The purpose of the decreasing function is to ensure that the distance between the BMU and its neighboring neurons is the closest. This function allows the BMU and the nearest neuron to adjust the distance. Time variable is also considered in SOM which stands for the learning rate or learning speed to ensure that the learning process is terminated within a limited time period. In addition, this research utilizes the widely applied neighborhood kernel, the Gaussian function. This function in the learning process of SOM enables neighboring neurons to move closer to each other and generate data clusters of high homogeneity. In summary, this research utilizes the concept of SOM as the first step for grouping data. We assumed that highly homogeneous data could be clustered efficiently by using SOM. In other words, the generated clusters represent highly homogeneous inside and heterogeneous outside.

\section{Decision Trees}

Decision tree is the tool for decision support by representing a tree with possible consequences and possibility (Fig. 3). Decision tree includes three major components: decision nodes, chance nodes, and end nodes (Quinlan, 1986). Decision tree is widely used in 
operations research, data mining, and machine learning areas. A decision tree can be learned by splitting the source into subsets based on attributes. The process to construct a tree is a recursive splitting (growing), which is also considered a top-down induction process. First, selecting of the splits (nodes) for the tree. Second, determining when to terminate or continue splitting. Third, assigning each terminal node to a class. Once the tree has been constructed, the pruning phase is conducted. In addition, there are three requirements for decision threes (1) object or case must be expressible in terms of a fixed collection of properties or attributes, (2) the target function has discrete output values (e.g., boolean or multi-class), and (3) enough training cases should be provided to learn the model.

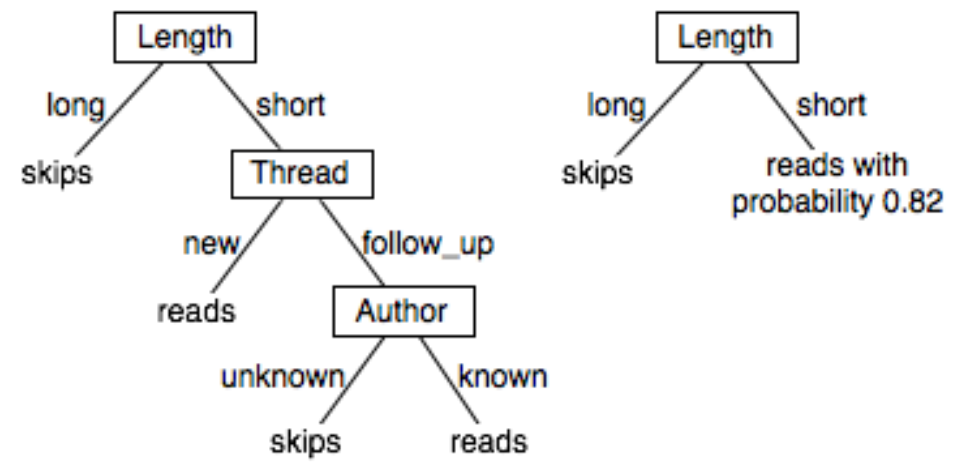

Figure 3 An Example of Decision Trees

Decision tree is also a classifier in the form of a tree structure. The major criterion is choosing the most useful attribute for classifying examples. Decision tree has certain advantages. First, the generated rules are understandable. Second, decision tree can perform classification without much computation. Third, decision tree can deal with continuous and categorical attributes. Fourth, decision tree is robust to the effect of outliers. However, decision tree also has some limitations. For example, decision tree performs poorly with many class and small data. Some algorithms are time-consuming to train data $\mathrm{n}$ pruning phase. Furthermore, tree replication may also be the problem of decision trees.

Decision tree is widely used in common decision making situations. Sheng, Wei, Hu, and Chang (2000) used decision tree in pattern image to retrieve knowledge. Delen, Kuzey, and Uyar (2013) measured firm performance with financial ratios by decision tree approach. Decision trees were also used to select the winding material in power transformers (Georgilakis et al., 2007), build energy demand modeling (Yu et al., 2010), and food courts demand prediction (Bozkir and Sezer, 2011). In this research, decision tree is used to analyze the rules of each cluster and identify significant personal traits that are associated with beauty or happiness.

\section{DATA ANALYSIS \\ Questionnaire and Data Collection}

This research designed a simple questionnaire with three parts: demographics (12 items), personal characteristics (20 items), and working performance (11 items). The second and third parts used 5-point Likert scale from strongly disagree to strongly agree. In addition, we sum the score between 13 to 20 in order to estimate the score of happiness. This research transforms the summed score into 5 intervals: 1 for strongly low (originally 8 to 19), 2 for 
low (originally 20-29), 3 for medium (originally 30-34), 4 for high (originally 35-39), and 5 for strongly high (originally above 40). This research uses two female investigators to collect data. The reason is to provide objective mindset to give fair beauty scores of samples. The beauty scores will be averaged finally. The investigators distribute the questionnaires in person and online. The participants will be asked to provide Facebook accounts in order to reveal the pictures if they finish the questionnaire online. The beauty score is between 1 and 5 (homely, quite plain, average looks, good-looking, and strikingly handsome or beautiful) based on the concept from Hamermesh (2011). Totally valid 505 samples are collected from July 2012 to September 2012. Moreover, we simply tested the questionnaire for reliability and the result shows Cronbach's alpha is 0.943 .

\section{Demographics}

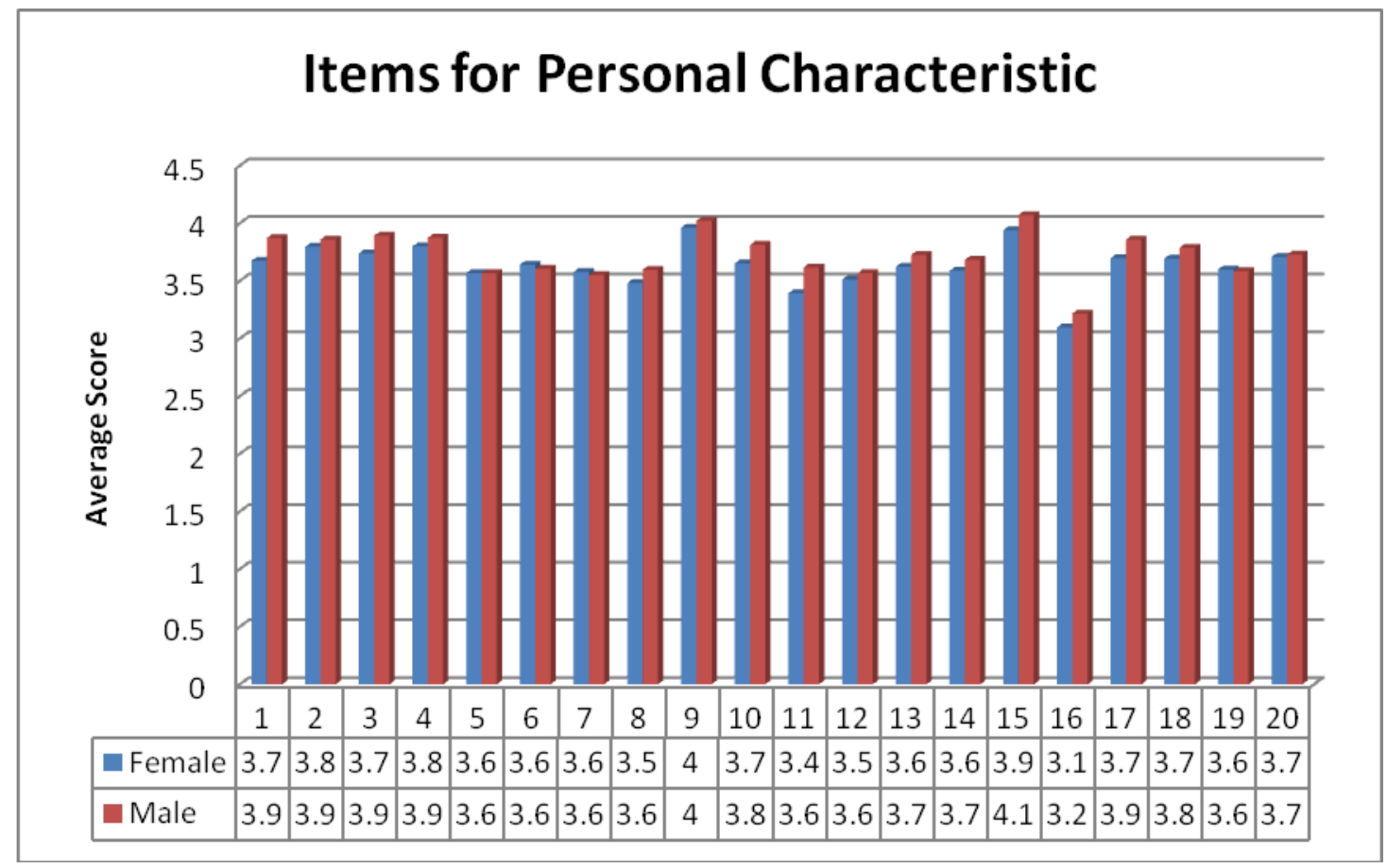

Figure 4 Average score for personal characteristics

Among the items to measure personal characteristics, the results reveal that the participants considered themselves are highly team players and better at interacting with friends (Fig. 4). The averaged scores for males are also higher than females. According to social exchange theory, this indicates that males emphasize more on interpersonal relationships in workplaces than females that may generate more benefits. 


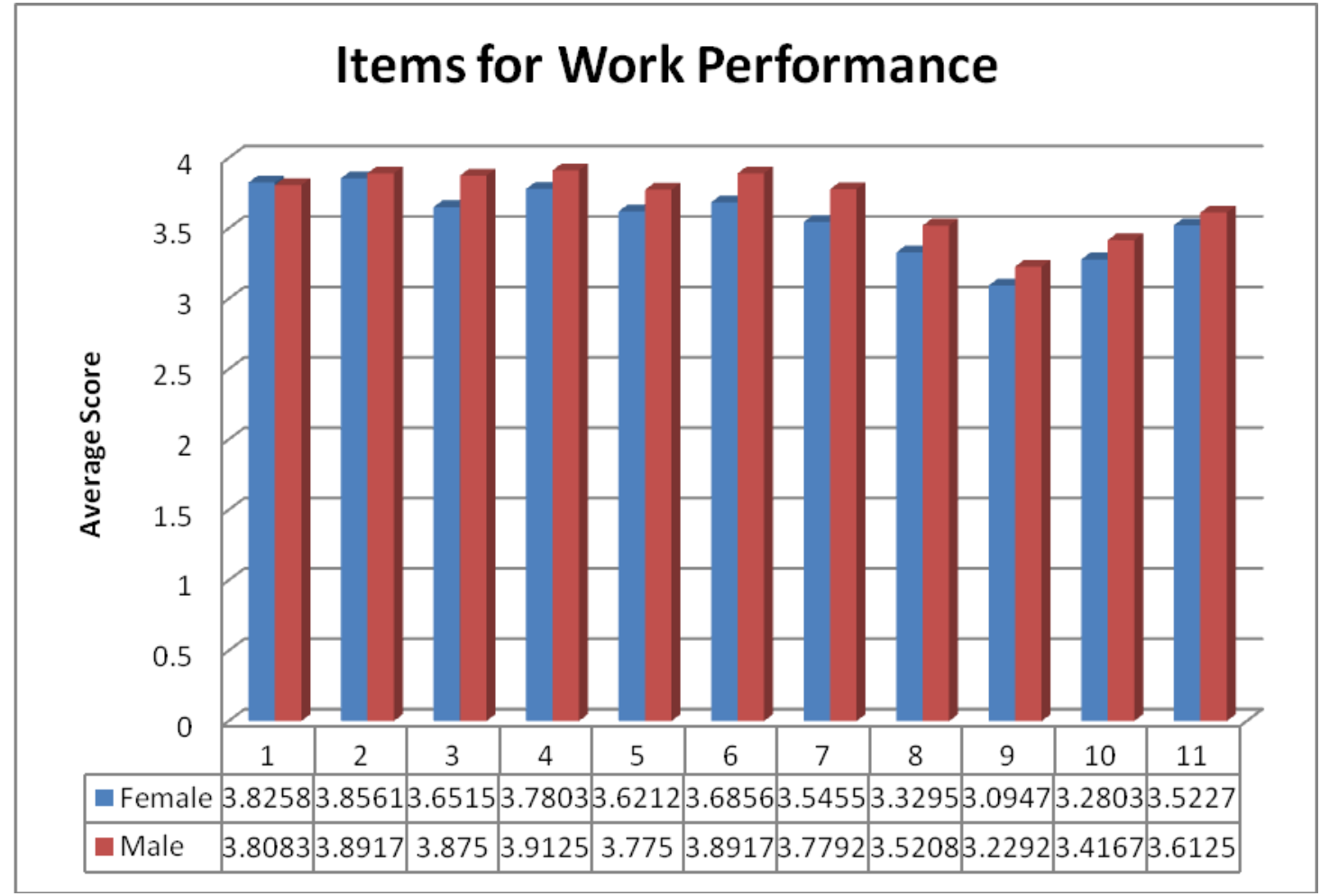

Figure 5 Average score for work performance

Among the items to measure work performance (Fig. 5), female participants considered their jobs are less variety, challenging, recognized and satisfied, authorized, and the unbalance between salary and effort. According to ceiling effect, females are generally arranged to deal with supportive and in-complicated jobs in eastern culture, which is in accordance with our results.

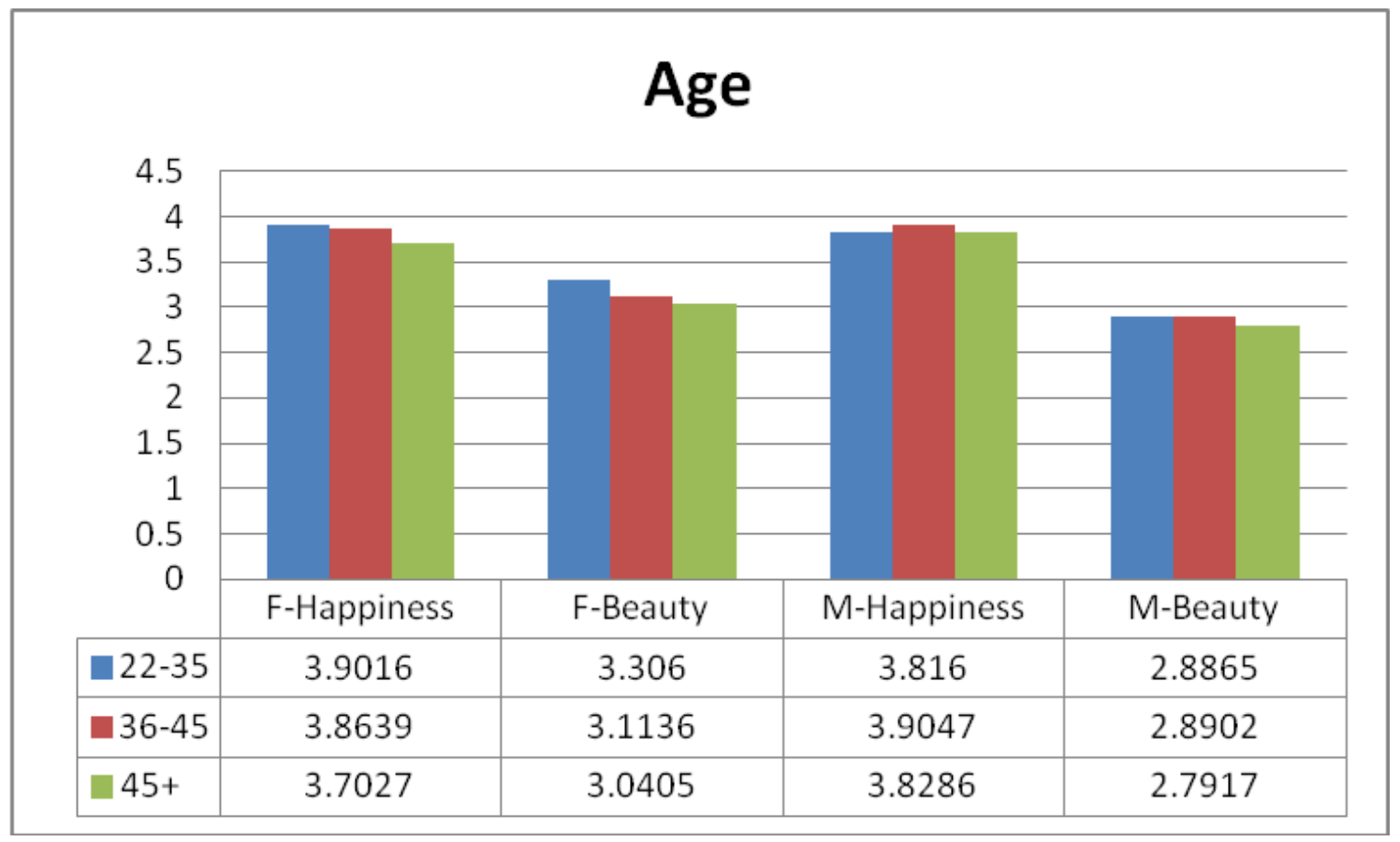

Figure 6 Results of beauty and happiness in age distribution 
The results show the score of happiness decreases when the age increases for females (Fig. 6). The reason is related to career promotion and personal issue. Males generally have better promotion opportunities in eastern cultures. In addition, gender discrimination exists in most workplaces and results in less self-esteem or life achievement for females. On the other hand, males are happy between 36 and 45 years old. The reason is that this interval of age is the peak of promotion in career and males have more opportunities to get promoted at this interval, which may make them happier. After 45 years old, the score of happiness moves to the baseline. The results also show the score of beauty decreases significantly by increasing age for females. Males have slightly changes for the score of beauty by age. The reason is females put more efforts on families and children, which means they spend less time on putting on makeup or pay more attention to their appearances.

The scores reveal females (3.8674) are happier than males (3.8333). According to the report, there is a gene called MAOA that may influence the human brains in terms of happiness. In particular, this gene has no effect on males. The scores also reveal females (3.1534) care more about their appearances than males (2.8561). In eastern culture, especially for Japan, South Korea, and Taiwan, females start to put on makeup in their teenage years and are willing to spend more money on cosmetics and clothing than males. Hence, our result is in accordance with the phenomenon.

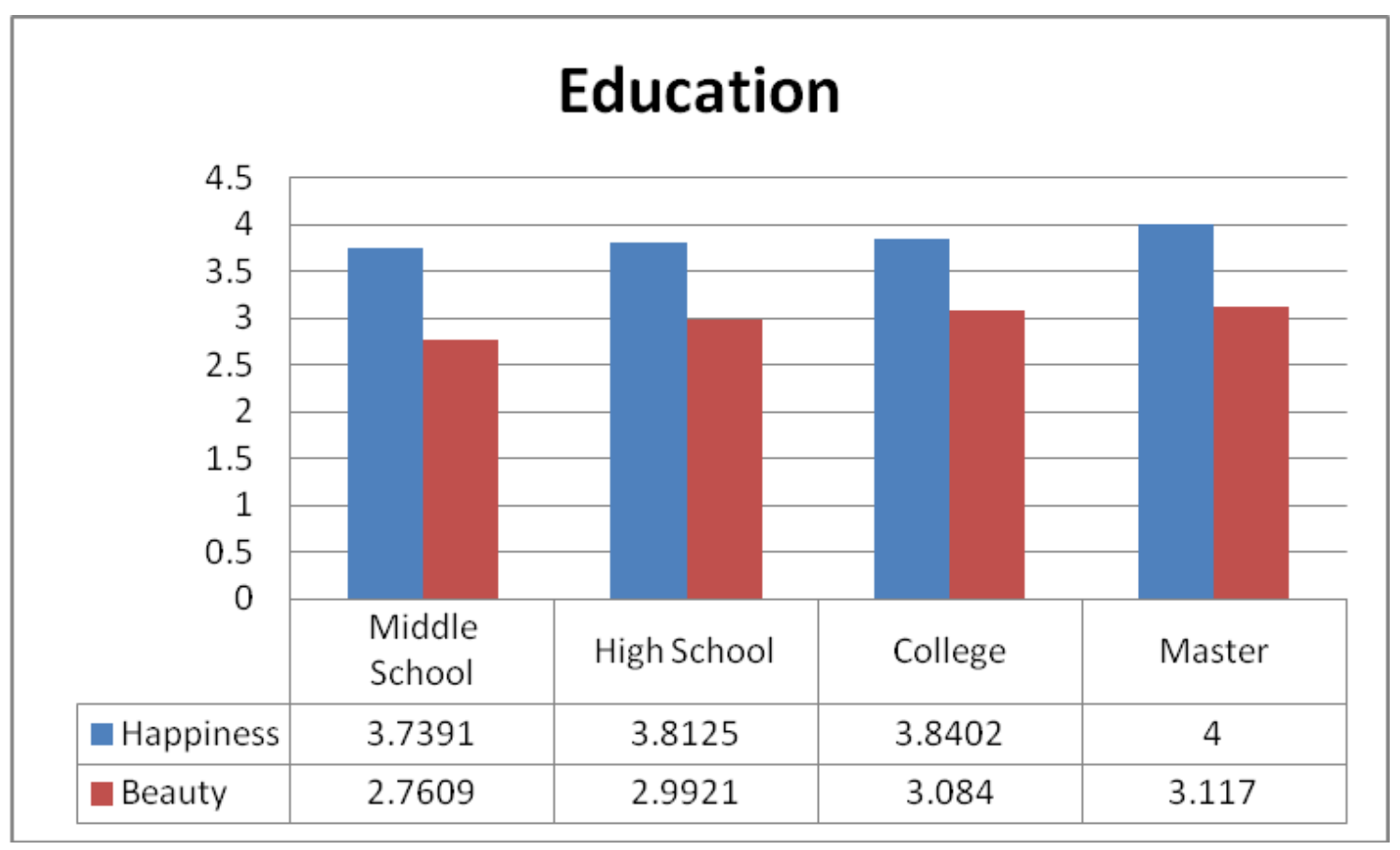

Figure 7 Results of beauty and happiness in education

Our results show people feel happier and look much prettier if the level of education is higher (Fig. 7). According to Maslow Theory, people feel happy if they fulfilled their needs. Higher level of education can make people interact with more different background of people. Thus, the opportunity to take into account, their appearance and beauty increases. The result shows married people (3.8281) are slightly happier than single people (3.8913). The reason is married people extend more relationships from families to society and discover belongingness from love. That is, they feel happier than single people. On the other hand, 
single people (3.1047) look much prettier than married people (2.9918). The reason is single people have more private time and the needs for seeking life partner which force them to pay closer attention to their body figure and appearance. Married people care more about families and spend less private time on their appearance. In particular, people have kids feel happier but look less beautiful. If they don't have kids, they spend more time on taking care of body figure and appearance, which may make them look much prettier than people who have kids.

\section{Results of Clustering}

This research utilizes Self-Organization Maps and Decision Tree to analyze the collected data. SOM is an unsupervised learning approach by neural networks that can allows data get closer for internal high similarity of a cluster and external high discrimination among clusters. Decision tree is a rule-based approach to classify data by generating rules. The feature is to observe the invisible relationships among attributes of data. This work provides an integrated framework to cluster data first and analyze each cluster in details. In addition, two indicators are used for decision tree to measure reliability and validity: support and confidence. Support means the percentage of the rule among all data. If the percentage is high, the rule is more reliable. Confidence means the precision of the rule. If the percentage is high, the rule is more valid.

We give $3 \times 3$ as maximum of clusters for SOM and the results show 4 clusters are generated accordingly (Fig. 8). The number of valid data for each cluster is 60 (cluster 1), 99 (cluster 2), 28 (cluster 3), and 306 (cluster 4). Because of the limited number of data for cluster 3 , only cluster 1 , cluster 2 , and cluster 4 will be used for classification of decision tree. This research analyzes each cluster by two ways. Beauty and happiness will be the target class individually for decision tree. That is, the results will be the relationship between factors and beauty as well as relationship between factors and happiness.

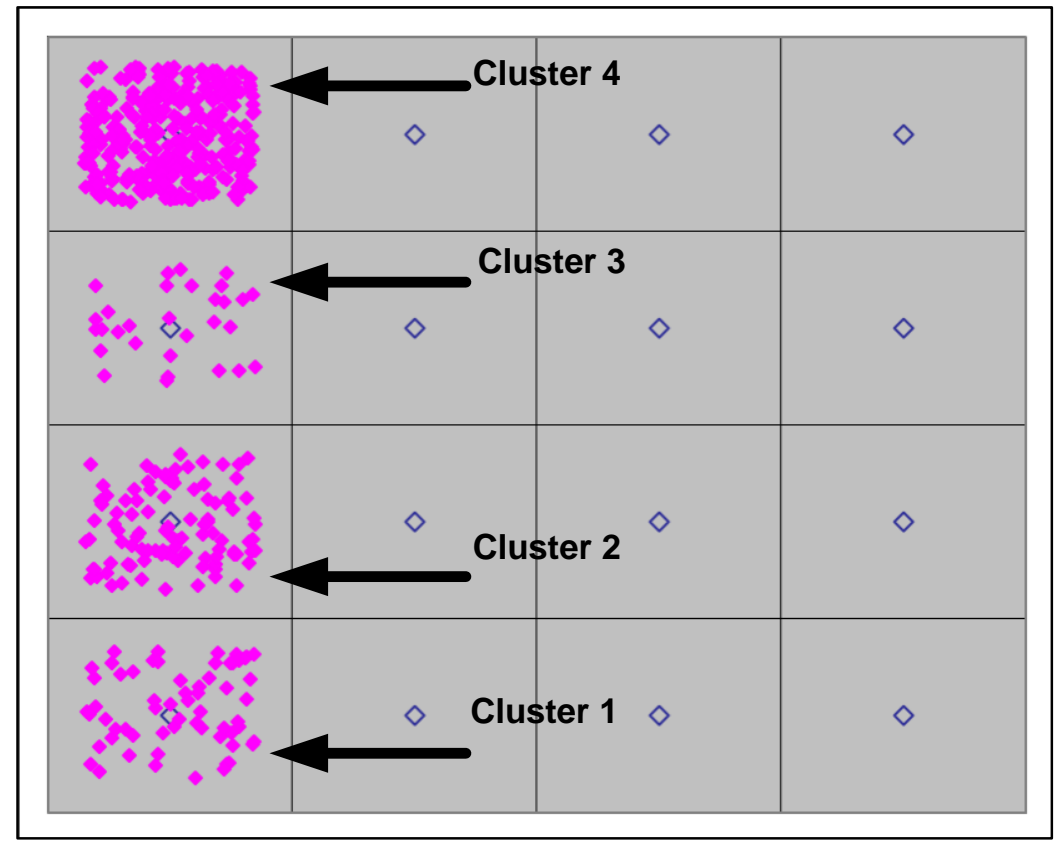

Figure 8 Results of SOM clustering

The results reveal participants from cluster 1 and cluster 2 are older than cluster 3 and 


\section{MIMacrothink}

International Journal of Human Resource Studies

ISSN 2162-3058

2013, Vol. 3, No. 4

cluster 4 that the majority of age is above 36 years old (Table 1). Most participants are married in cluster 1 and cluster 2. Cluster 3 and cluster 4 are majorly formed by young people. Particularly, cluster 3 is a young female cluster and around $96.7 \%$ of the people in cluster 4 are single. Participants from cluster 1 and cluster 2 have more working experience than those in cluster 3 and cluster 4, while half percent are rookies in cluster 4 (working experience is 1 to 5 years). The job positions from participants in cluster 1 are managers and employees, while participants from cluster 3 are more low-level managers. Participants from cluster 2 and cluster 4 are more basic employees (over 58\%).

The score of happiness is mostly over 4 for cluster 1 (near 92\%), over 3 for cluster 2 (near 86\%), over 4 for cluster 3 (near 89\%), and over 3 for cluster 4 (near 90\%). Participants are happy from cluster 1 and cluster 2 because they have good positions at work, married, and have children. This leads to a kind of fulfillment for high level needs of life. Participants from cluster 3 and cluster 4 are happy although they are young, single, and have no burden to take care of children. They may have good friendships in society with basic fulfillment of needs of life.

The score of beauty is mostly between 3 and 3 for cluster 1 (near 75\%), between 3 and 4 for cluster 2 (near $81 \%$ ), between 3 and 4.5 for cluster 3 (near 100\%), and between 3 and 5 for cluster 4 (near $71 \%$ ). Aged people who are married and have children pay less attention on their appearance and the way they dress. That is, the score of beauty for cluster 1 and cluster 2 are lower than cluster 3 and cluster 4. Participants from cluster 3 are majorly females who may pay more attention on their appearance and the way they dress seriously either at work or daily life. In addition, participants from cluster 4 are mostly between 22 to 35 years old. People in these ages group pay highly attention to their appearance and the way they dress in order to draw others attention. No matter with our without makeup, young people have higher score in beauty than aged people. In summary, we name cluster 1 as an "aged with reputation group", cluster 2 as a "normal group", cluster 3 as a "young female group", and cluster 4 as a "young and rookie group".

Table 1 Summary of clustering results

\begin{tabular}{|c|c|c|c|c|c|c|c|c|c|}
\hline & \multicolumn{2}{|c|}{ Cluster 1} & \multicolumn{2}{|c|}{ Cluster 2} & \multicolumn{2}{|c|}{ Cluster 3} & \multicolumn{2}{|c|}{ Cluster 4} \\
\hline & & Count & Percentage & Count & Percentage & Count & Percentage & Count & Percentage \\
\hline \multirow[t]{2}{*}{ Gender } & Female & 26 & $43.333 \%$ & 56 & $56.566 \%$ & 24 & $85.714 \%$ & 152 & $49.673 \%$ \\
\hline & Male & 34 & $56.66 \%$ & 43 & $43.434 \%$ & 4 & $14.286 \%$ & 154 & $50.327 \%$ \\
\hline \multirow[t]{3}{*}{ Age } & $22-35$ & 3 & $5 \%$ & 27 & $27.272 \%$ & 24 & $85.714 \%$ & 289 & $94.444 \%$ \\
\hline & $36-45$ & 24 & $40 \%$ & 39 & $39.394 \%$ & 4 & $14.286 \%$ & 14 & $4.575 \%$ \\
\hline & $45+$ & 33 & $55 \%$ & 33 & $33.333 \%$ & 0 & 0 & 3 & $0.98 \%$ \\
\hline \multirow{4}{*}{$\begin{array}{l}\text { Working } \\
\text { Year }\end{array}$} & $1-$ & 0 & 0 & 2 & $2.02 \%$ & 1 & $3.571 \%$ & 85 & 27.778 \\
\hline & $1-5$ & 2 & $3.333 \%$ & 18 & $18.182 \%$ & 9 & $32.143 \%$ & 164 & 53.595 \\
\hline & $6-10$ & 14 & $23.333 \%$ & 26 & $26.263 \%$ & 9 & $32.143 \%$ & 39 & 12.745 \\
\hline & $10+$ & 44 & $73.333 \%$ & 53 & $53.535 \%$ & 9 & $32.143 \%$ & 18 & $5.882 \%$ \\
\hline Position & Employee & 13 & $21.667 \%$ & 58 & $58.586 \%$ & 6 & $21.429 \%$ & 207 & $67.647 \%$ \\
\hline
\end{tabular}




\section{Macrothink $\Delta$ Institute ${ }^{\text {tm }}$}

International Journal of Human Resource Studies

ISSN 2162-3058

2013, Vol. 3, No. 4

\begin{tabular}{|c|c|c|c|c|c|c|c|c|c|}
\hline & Assistant & 2 & $3.333 \%$ & 9 & $9.09 \%$ & 3 & $10.714 \%$ & 33 & $10.784 \%$ \\
\hline & $\begin{array}{l}\text { Group } \\
\text { Leader }\end{array}$ & 5 & $8.333 \%$ & 8 & $8.08 \%$ & 1 & $3.571 \%$ & 24 & $7.843 \%$ \\
\hline & $\begin{array}{l}\text { Low-level } \\
\text { Manager }\end{array}$ & 11 & $18.333 \%$ & 13 & $13.131 \%$ & 12 & $42.857 \%$ & 32 & $10.458 \%$ \\
\hline & $\begin{array}{l}\text { Middle } \\
\text { Manager }\end{array}$ & 13 & $21.667 \%$ & 7 & $7.071 \%$ & 4 & $14.286 \%$ & 7 & $2.288 \%$ \\
\hline & $\begin{array}{l}\text { High-level } \\
\text { manager }\end{array}$ & 16 & $26.667 \%$ & 4 & $4.04 \%$ & 2 & $7.143 \%$ & 3 & $0.98 \%$ \\
\hline Marriage & Single & 0 & 0 & 5 & $5.051 \%$ & 15 & $53.571 \%$ & 294 & $96.078 \%$ \\
\hline & Married & 60 & $100 \%$ & 94 & $94.95 \%$ & 13 & $46.429 \%$ & 12 & $3.922 \%$ \\
\hline Children & No & 0 & 0 & 14 & $14.141 \%$ & 24 & $85.714 \%$ & 305 & $99.673 \%$ \\
\hline & Yes & 60 & $100 \%$ & 85 & $85.859 \%$ & 4 & $14.286 \%$ & 1 & $0.327 \%$ \\
\hline Happiness & $1(8-19)$ & 0 & 0 & 0 & 0 & 0 & 0 & 2 & $0.654 \%$ \\
\hline & $2(20-29)$ & 0 & 0 & 14 & $14.141 \%$ & 0 & 0 & 27 & $8.824 \%$ \\
\hline & $3(30-34)$ & 5 & $8.333 \%$ & 38 & $\mathbf{3 8 . 3 8 4} \%$ & 3 & $10.714 \%$ & 90 & $29.412 \%$ \\
\hline & $4(35-39)$ & 21 & $35 \%$ & 36 & $36.364 \%$ & 7 & $25 \%$ & 102 & $\mathbf{3 3 . 3 3 3} \%$ \\
\hline & $5(40+)$ & 34 & $56.667 \%$ & 11 & $11.111 \%$ & 18 & $64.286 \%$ & 85 & $27.778 \%$ \\
\hline Beauty & 1.5 & 0 & 0 & 0 & 0 & 0 & 0 & 0 & 0 \\
\hline & 2 & 6 & $10 \%$ & 6 & $6.061 \%$ & 0 & 0 & 23 & $7.516 \%$ \\
\hline & 2.5 & 9 & $15 \%$ & 12 & $12.121 \%$ & 0 & 0 & 28 & $9.15 \%$ \\
\hline & 3 & 36 & $60 \%$ & 67 & $67.677 \%$ & 16 & $57.143 \%$ & 171 & $55.882 \%$ \\
\hline & 3.5 & 5 & $8.333 \%$ & 7 & $7.071 \%$ & 5 & $17.857 \%$ & 47 & $15.359 \%$ \\
\hline & 4 & 4 & $6.667 \%$ & 7 & $7.071 \%$ & 3 & $10.7142 \%$ & 30 & $9.804 \%$ \\
\hline & 4.5 & 0 & 0 & 0 & 0 & 4 & $14.286 \%$ & 3 & $0.98 \%$ \\
\hline & 5 & 0 & 0 & 0 & 0 & 0 & 0 & 4 & $1.307 \%$ \\
\hline
\end{tabular}

\section{Classification Rules of Cluster 1}

Firstly, we consider beauty as the class for decision tree classification. The results reveal 6 rules for cluster 1 (Table 2). In particular, rule 1 shows the score of beauty is 2.5 if they are self employed. The reason is most companies require employees to dress up and put on makeup, except those who are self employed. Thus, people pay less attention and put less effort on their appearance and the way they dress if they have more freedom at work. Rule 5 and 6 show the look of people is fair (score is 3 ) if they are extroversion. The percentages of confidence for rule 1 , rule 5 , and rule 6 are higher than $60 \%$, which are sufficient for explanation. 
Table 2 Results of decision tree classification for cluster 1 (beauty)

\begin{tabular}{|c|ccccc|} 
Rule Summary Table & & \multicolumn{2}{c|}{ \# Rules } & 6 \\
\hline Rule ID & Class & Length & Support & Confidence & Capture \\
\hline $\mathbf{1}$ & $\mathbf{2 . 5}$ & $\mathbf{1}$ & $\mathbf{1 0 . 0 \%}$ & $\mathbf{6 0 . 0 \%}$ & $\mathbf{3 7 . 5 \%}$ \\
2 & 3 & 1 & $6.0 \%$ & $66.7 \%$ & $6.9 \%$ \\
3 & 3 & 1 & $10.0 \%$ & $80.0 \%$ & $13.8 \%$ \\
4 & 3 & 1 & $18.0 \%$ & $55.6 \%$ & $17.2 \%$ \\
$\mathbf{5}$ & $\mathbf{3}$ & $\mathbf{1}$ & $\mathbf{6 0 . 0 \%}$ & $\mathbf{6 0 . 0 \%}$ & $\mathbf{6 2 . 1 \%}$ \\
$\mathbf{6}$ & $\mathbf{3}$ & $\mathbf{1}$ & $\mathbf{9 6 . 0 \%}$ & $\mathbf{6 0 . 4 \%}$ & $\mathbf{1 0 0 . 0 \%}$ \\
\hline
\end{tabular}

Secondly, we consider happiness as the class for decision tree classification. The results reveal 6 rules for cluster 1 (Table 3). Rule 1 shows the score of happiness is 5 if people strongly agree they smile and laugh every day. The reason is people who laugh and smile more often are easygoing and friendly, which makes them happier. Rule 2 and rule 4 show people work in the marketing department and who are salespersons are extremely happy (score is 5). The reason is marketing people and salespersons are considered extroversion and they are more confident to interact with others. Rule 3 indicates the score of happiness is 4 if people work at MIS department. Rule 5 and rule 6 reveal the score of happiness is higher than 4 if the position of job is management level. The reason is more authorization results in more achievement and happiness. The percentages of confidence are higher than $75 \%$ except rule 6 (58.3\%), which are also sufficient for explanation.

Table 3 Results of decision tree classification for cluster 1 (happiness)

\begin{tabular}{|cccccc|} 
Rule Summary Table & & \# Rules & 6 \\
\hline Rule ID & Class & Length & Support & Confidence & Capture \\
\hline 1 & 5 & 1 & $42.9 \%$ & $100.0 \%$ & $67.7 \%$ \\
2 & 5 & 1 & $12.2 \%$ & $83.3 \%$ & $16.1 \%$ \\
3 & 4 & 1 & $4.1 \%$ & $100.0 \%$ & $14.3 \%$ \\
4 & 5 & 1 & $24.5 \%$ & $75.0 \%$ & $29.0 \%$ \\
5 & 5 & 1 & $16.3 \%$ & $87.5 \%$ & $22.6 \%$ \\
6 & 4 & 1 & $24.5 \%$ & $58.3 \%$ & $50.0 \%$ \\
\hline
\end{tabular}

\section{Classification Rules of Cluster 2}

Firstly, we consider beauty as the class for decision tree classification. The results reveal 15 rules for cluster 2 (Table 4). Particularly, rule 3 shows the score of beauty is 4 if people work at construction industry. The reason is the business in construction industry is huge; thus, people may pay more attention on their appearance and the way they dress, and their attitude. The impression of this industry should be stern and positive. Other rules show no significant findings for beauty. Among 15 rules, only rule 3 is meaningful for explanation and the percentage of confidence is $66.7 \%$, which is sufficient for explanation. 
Table 4 Results of decision tree classification for cluster 2 (beauty)

\begin{tabular}{|cccccc|}
\multicolumn{2}{c}{ Rule Summary Table } & & \multicolumn{2}{c|}{ \# Rules } & 15 \\
\hline Rule ID & Class & Length & Support & Confidence & Capture \\
\hline 0 & 3 & 0 & $100.0 \%$ & $62.7 \%$ & $100.0 \%$ \\
1 & 3 & 1 & $13.3 \%$ & $90.0 \%$ & $19.1 \%$ \\
2 & 3 & 1 & $6.7 \%$ & $80.0 \%$ & $8.5 \%$ \\
3 & 4 & $\mathbf{1}$ & $\mathbf{4 . 0 \%}$ & $\mathbf{6 6 . 7 \%}$ & $\mathbf{2 8 . 6 \%}$ \\
4 & 3 & 1 & $4.0 \%$ & $100.0 \%$ & $6.4 \%$ \\
$\ldots$ & $\ldots$ & $\ldots$ & $\ldots$ & $\ldots$ & $\ldots$
\end{tabular}

Secondly, we consider happiness as the class for decision tree classification. The results reveal 5 rules for cluster 2 (Table 5). Rule 1 shows the score of happiness is 4 if people are salespersons. The reason is salesperson are considered extraversion and easy to get the deal that may earn more benefits. More money may bring more happiness. Rule 2 indicates the score of happiness is 3 the age is more than 45. This may explain the happiness will not decrease when the age increases. Rule 4 shows the score of happiness is 5 if people satisfy their existing life $(>=5)$ and feel valuable and meaningful of life $(>=4)$. Rule 5 indicates the score of happiness is 4 if people laugh and smile every day $(>=4)$. The percentages of confidence of all rules are higher than 50\%, which are still sufficient for explanation.

Table 5 Results of decision tree classification for cluster 2 (happiness)

\begin{tabular}{|c|c|c|c|c|c|}
\hline \multicolumn{4}{|c|}{ Rule Summary Table } & \multicolumn{2}{|l|}{ \# Rules } \\
\hline Rule ID & Class & Length & Support & Confidence & Capture \\
\hline 1 & 4 & 1 & $21.4 \%$ & $72.2 \%$ & $43.3 \%$ \\
\hline 2 & 3 & 1 & $35.7 \%$ & $53.3 \%$ & $51.6 \%$ \\
\hline 3 & 3 & 1 & $13.1 \%$ & $54.5 \%$ & $19.4 \%$ \\
\hline 4 & 5 & 2 & $6.0 \%$ & $100.0 \%$ & $50.0 \%$ \\
\hline 5 & 4 & 1 & $51.2 \%$ & $62.8 \%$ & $90.0 \%$ \\
\hline
\end{tabular}

\section{Classification Rules of Cluster 4}

First, we consider beauty as the class for decision tree classification. The results reveal 24 rules for cluster 4 (Table 6). Particularly, rule 1 shows the score of beauty is 2 if people work in traditional industry such as agriculture, forestry, fishery, and animal husbandry mine. The reason is people pay extremely less attention on look in these industries. Rule 10 reveals the score of beauty is 3 if the position is non-management employee. The reason is that non-management employees don't have to dress up and put on makeup for better appearance, on the other hand, managers have to contact more people with good expression. Cluster 4 has the most data and only rule 1 and rule 10 are meaningful. The percentages of confidence are $66.7 \%$ (rule 1) and $55.2 \%$ (rule 10), which are higher than $50 \%$ of threshold. 
Table 6 Results of decision tree classification for cluster 4 (beauty)

\begin{tabular}{|cccccc|} 
Rule Summary Table & & \multicolumn{2}{c|}{ \# Rules } & 24 \\
\hline Rule ID & Class & Length & Support & Confidence & Capture \\
\hline $\mathbf{1}$ & $\mathbf{2}$ & $\mathbf{1}$ & $\mathbf{1 . 2 \%}$ & $\mathbf{6 6 . 7 \%}$ & $\mathbf{9 . 5 \%}$ \\
2 & 3 & 1 & $2.0 \%$ & $60.0 \%$ & $2.2 \%$ \\
$\ldots$ & $\ldots$ & $\ldots$ & $\ldots$ & $\ldots$ & $\ldots$ \\
9 & 3 & 1 & $14.7 \%$ & $59.5 \%$ & $15.8 \%$ \\
$\mathbf{1 0}$ & $\mathbf{3}$ & $\mathbf{1}$ & $\mathbf{6 8 . 5 \%}$ & $\mathbf{5 5 . 2 \%}$ & $\mathbf{6 8 . 3 \%}$ \\
11 & 3 & 1 & $28.7 \%$ & $51.4 \%$ & $26.6 \%$ \\
\hline
\end{tabular}

Second, we consider happiness as the class for decision tree classification. The results reveal 13 rules for cluster 4 (Table 7). Rule 1 shows the score of happiness is 4 if people work in traditional industry such as agriculture, forestry, fishery, and animal husbandry mine. The reason is people don't have to worry about unemployment issue and those industries are combined with new creative ideas recently such as tourist farm. Rule 3 indicates the score of happiness is 4 if the score of beauty is 4.5 . People have more confidence in their appearance with inner beauty may affect outer beauty. In this case, people feel happy by high confidence and good appearance. Rule 6 reveals the score of happiness is 4 if people work at hospitality industry. The reason is hospitality industry has more creation and customization and is not the routine jobs and full of challenges. More achievements will be generated and results in more happiness. Rule 9 shows the score of happiness is 3 if the score of beauty is 5 . This is an interesting issue that people usually don't like others who are extremely beautiful or handsome at workplace. Consequently, less happiness occurred in this situation. Rule 12 indicates the score of happiness is 5 if people are self employed. The reason is high freedom at work results in more happiness. The percentages of explainable rules are all higher than $50 \%$, which provide valid ability for explanation.

Table 7 Results of decision tree classification for cluster 1 (happiness)

\begin{tabular}{|c|ccccc|}
\multicolumn{1}{l}{ Rule Summary Table } & & \multicolumn{2}{c|}{ \# Rules } & 13 \\
\hline Rule ID & Class & Length & Support & Confidence & Capture \\
\hline $\mathbf{1}$ & $\mathbf{4}$ & $\mathbf{1}$ & $\mathbf{1 . 2 \%}$ & $\mathbf{6 6 . 7 \%}$ & $\mathbf{2 . 4 \%}$ \\
2 & 4 & 1 & $2.0 \%$ & $60.0 \%$ & $3.7 \%$ \\
$\mathbf{3}$ & $\mathbf{4}$ & $\mathbf{1}$ & $\mathbf{1 . 2 \%}$ & $\mathbf{6 6 . 7 \%}$ & $\mathbf{2 . 4 \%}$ \\
4 & 2 & 1 & $9.6 \%$ & $66.7 \%$ & $69.6 \%$ \\
5 & 4 & 1 & $9.2 \%$ & $52.2 \%$ & $14.6 \%$ \\
$\mathbf{6}$ & $\mathbf{4}$ & $\mathbf{1}$ & $\mathbf{3 . 6 \%}$ & $\mathbf{5 5 . 6 \%}$ & $\mathbf{6 . 1 \%}$ \\
$\mathbf{7}$ & 5 & 1 & $12.9 \%$ & $87.5 \%$ & $40.0 \%$ \\
8 & 3 & 1 & $34.5 \%$ & $60.5 \%$ & $71.2 \%$ \\
$\mathbf{9}$ & $\mathbf{3}$ & $\mathbf{1}$ & $\mathbf{1 . 2 \%}$ & $\mathbf{6 6 . 7 \%}$ & $\mathbf{2 . 7 \%}$ \\
10 & 5 & 1 & $14.5 \%$ & $80.6 \%$ & $41.4 \%$ \\
11 & 3 & 1 & $46.6 \%$ & $55.2 \%$ & $87.7 \%$ \\
$\mathbf{1 2}$ & $\mathbf{5}$ & $\mathbf{1}$ & $\mathbf{4 . 4 \%}$ & $\mathbf{5 4 . 5 \%}$ & $\mathbf{8 . 6 \%}$ \\
13 & 5 & 1 & $34.1 \%$ & $50.6 \%$ & $61.4 \%$ \\
\hline
\end{tabular}




\section{DISCUSSIONS}

We summarize the result of degree of happiness in Table 8. In cluster 1, the degree of happiness is between 4 and 5 , which means people are happier than other clusters. The reason is the age is older and the thinking is more positive for life, work, and family. In cluster 2, the distribution of age is on average that results in middle degree of happiness. In cluster 3 , most participants are female who usually are happier than male. In cluster 4, participants are rookies in workplace and the degree of happiness is in the middle due to unstable job and no pressure from family and finance.

Table 8 Summary of four clusters

\begin{tabular}{|l|l|l|l|l|l|}
\hline \multicolumn{2}{|c|}{} & $\begin{array}{l}\text { Cluster } \\
1\end{array}$ & $\begin{array}{l}\text { Cluster } \\
\mathbf{2}\end{array}$ & $\begin{array}{l}\text { Cluster } \\
\mathbf{3}\end{array}$ & $\begin{array}{l}\text { Cluster } \\
\mathbf{4}\end{array}$ \\
\hline \multirow{2}{*}{$\begin{array}{l}\text { Degree } \\
\text { of } \\
\text { happiness }\end{array}$} & 1 & 0 & 0 & 0 & $0.654 \%$ \\
\cline { 2 - 6 } & 2 & 0 & $14.141 \%$ & 0 & $8.824 \%$ \\
\cline { 2 - 6 } & 3 & $8.333 \%$ & $38.384 \%$ & $10.714 \%$ & $29.412 \%$ \\
\cline { 2 - 6 } & 4 & $35 \%$ & $36.364 \%$ & $25 \%$ & $33.333 \%$ \\
\cline { 2 - 6 } & 5 & $56.667 \%$ & $11.111 \%$ & $64.286 \%$ & $27.778 \%$ \\
\hline
\end{tabular}

Particularly, the degree of happiness of senior managers in cluster 2 (2.5) is lower than other clusters ( 4.438 for cluster $1,4.5$ for cluster 3 , and 4.33 for cluster 4 ). On the other hand, the characteristics of senior manager such as adventure of spirit, decision making ability, emotion management, and executive ability are not high. The satisfaction of job is also lower than other clusters. Hence, we infer participants do not fit their current job positions that may results in lower degree of happiness.

Although the occupation is mostly in service industry, cluster 3 has more than fifty percent of occupation in service industry and mostly female participants. The departments are dominated in marketing and sales, which result in higher degree of beauty. Females care about the appearance when working on site to give clients good first impression. This may result in good interpersonal relationship at work and increase the degree of happiness. Moreover, compared with cluster 1, participants from cluster 4 are mostly rookies at work and the degree of happiness in the middle. The reasons are unstable job and less experience that may cause nervous and negative emotions. The perceived difference between job expectation and perception is also the reason to cause lower degree of happiness.

\section{CONCLUSION AND LIMITATIONS}

This research investigates the correlation between beauty and happiness. The results reveal people feel happy if they have stable job and career. People who work at marketing or sales department in service industry have higher degree of beauty. The reason is most people have to deal with their clients in person. They have to make up or care more about the appearance for good impression. The degree of beauty is lower in other industries such as construction industry. Conversely, the appearance indeed influences the degree of happiness; particularly, women pay more attention to it. Rookie employees are less happier than senior managers because of more pressure at work. In addition, females are happier than males in 
general. The reason is that females satisfy their life more easily than males. People who have higher degree of beauty also have higher degree of happiness. The results confirms to the research of Hamermesh (2011) that handsome and beautiful people have more confidence that may result in happiness. This research expands to a different geographic location and deepens the correlation between beauty and happiness. After examining the samples, the results are in accordance with the existing findings of researches.

This research also has several limitations. First, the collected sample was mostly distributed in northern Taiwan. Although the some samples were from central and southern Taiwan, more samples will be needed to generalize the outcome in the future. Second, more personal traits can be added to increase the possibility of producing more rules from classification. Third, this research used two investigators to provide the degree of beauty for each participant. More investigators can be added to increase the fairness. The outcomes may be more convincing and generalizing. In summary, this research provides a first attempt to use combined data mining techniques in analyzing beauty and happiness. The results can be the basis for further researchers exploring deeper.

\section{REFERENCES}

Andreoni, J. and Petri, R., 2008. Beauty, gender and stereotypes: Evidence from laboratory experiments, Journal of Economic Psychology, 29(1) , pp. 73-93.

Astudillo, C. A. and oommen, B. J., 2011. Imposing tree-based topologies onto self organizing maps, Information Sciences, 181, 3798-3815.

Biddle, J. E. and Hamermesh, D. S., 1998. Beauty, Productivity and Discrimination, Lawyers' Looks and Lucre, Journal of Labor Economics, 16(1), pp. 172-201.

Bozkir, A. S., Sezer, E. A., 2011. Predicting food demand in food courts by decision tree approaches, Procedia Computer Science, 3, pp. 759-763

Croucher, J. S., 2009. Do attractive people have an advantage in business and in life?, European Journal of Management, 9(4).

Delen, D., Kuzey, C., and Uyar, A., 2013. Measuring firm performance using financial ratios: A decision tree approach, Expert Systems with Applications, 40(10), pp. 3970-3983.

Georgilakis, P. S., Gioulekas, A. T., Souflaris, A. T., 2007. A decision tree method for the selection of winding material in power transformers, Journal of Materials Processing Technology, 181(1-3), pp. 281-285.

Hamermesh, D. S. and Biddle, J. E., 1994. Beauty and Labor Market, The American Economic Review, 84(5), pp. 1174-1194.

Hamermesh, D. S., 2011. Beauty Pays: Why Attractive People Are More Successful, Princeton University Press.

Hamermesh, D. S. and Abrevaya, J., 2011. Beauty Is the Promise of Happiness?, working paper, National Bureau of Research.

Isa, D., Kallimani, V. P., and Lee, L. H., 2009. Using the self organizing map for clustering of text document, Expert Systems with Applications, 36, 9584-9591.

Kohonen, T., 1990. The Self-Organizing Map, Proceedings of the IEEE, 78(9), pp. 1464 -1480 . 
Kumar, P. R. and Ravi, V., 2007. Bankruptcy prediction in banks and firms via statistical and intelligent techniques - A Review, European Journal of Operational Research, 180, $1-28$.

Lagus, K., Honkela, T., Kaski, S., and Kohonen, T., 1996. Self-organizing maps of document collections: A new approach to interactive exploration, Neural Networks, 1(2), 238-243.

Liu, P., 2009. A self-organizing feature maps and data mining based decision support system for liability authentications of traffic crashes, Neurocomputing, 72, 2902-2908.

Moreno, D., Marco, P., and Olmeda, I., 2006. Self-organizing maps could improve the classification of Spanish mutual funds, European Journal of Operational Research, 174, 1039-1054.

Nohuddin, P. N. E., Coenen, F., Christley, R., Setzkorn, C., Patel, Y., and Williams, S., 2012. Finding "interesting" trends in social networks using frequent pattern mining and self organizing maps, Knowledge-Based Systems, 29, 104-113.

Pfann, G. A., Biddle, J. E. and Hamermesh, D. S., 2000. Business Success and Businesses' Beauty Capital, Economics Letters, 67(2), pp. 201-207

Quinlan, J. R., 1986. Induction of Decision Trees, Machine Learning, 1(1), pp 81-106.

Rhod, D. L., 2011. The Beauty Bias: The Injustice of Appearance in Life and Law, Oxford University Press, USA.

Rumelhart, D. E. and McClelland, J. L., 1986. Parallel Distributed Processing. (M. I. T. Press, Ed.) Foundations (Vol. 1, pp. 135-153). MIT Press.

Sheng, O. R. L., Wei, C.-P., Hu, P. J.-H., Chang, N., 2000. Automated learning of patient image retrieval knowledge: neural networks versus inductive decision trees, Decision Support Systems, 30(2), pp. 105-124.

Varian, H. R., 2006. The beauty premium: Why good looks pay, New York Times, April.

Yu, Z., Haghighat, F., Fung B. C. M., Yoshino, H., 2010. A decision tree method for building energy demand modeling, Energy and Buildings, 42 (10), pp. 1637-1646.

Zhao, X., Li, P., and Kohonen, T., 2011. Contextual self-organizing map: software for constructing semantic representations, Behavior Research Methods, 43(1), 77-88. 